\title{
Polymorphisms of matrix metalloproteinase-7 and -9 are associated with oral tongue squamous cell carcinoma
}

\author{
George João Ferreira do \\ NASCIMENTO(a) \\ Leorik Pereira da SILVA(b) \\ Felipe Rodrigues de MATOS(c) \\ Thayse Azevedo da SILVA(d) \\ Silvia Regina Batistuzzo de \\ MEDEIROS(e) iD $^{(e)}$ \\ Lélia Batista de SOUZA ${ }^{(f)}$ iD \\ Roseana de Almeida FREITAS(f)
}

(a) Universidade Federal de Campina Grande - UFCG, Biological Sciences Academic

Center, Patos, PB, Brazil.

(b) Universidade Federal do Amazonas -

UFAM, Health and Biotechnology Institute, Coari, AM, Brazil.

(c) Universidade Federal do Sergipe - UFS, Dentistry Department of Lagarto, Lagarto, SE, Brazil.

(d) Instituto Federal do Rio Grande do Norte IFRN, Parnamirim, RN, Brazil.

(e) Universidade Federal do Rio Grande do Norte - UFRN, Biosciences Center, Department of Cell Biology and Genetics, Natal, RN, Brazil.

(f) Universidade Federal do Rio Grande do Norte - UFRN, Postgraduate Program in Oral Pathology, Natal, RN, Brazil.

Declaration of Interests: The authors certify that they have no commercial or associative interest that represents a conflict of interest in connection with the manuscript.

Corresponding Author:

Roseana de Almeida Freitas

Email: roseanafreitas@hotmail.com

https://doi.org/10.1590/1807-3107bor-2021.vol35.0019

Submitted: February 11, 2020

Accepted for publication: June 8, 2020

Last revision: September 23, 2020

\begin{abstract}
Matrix degradation is an important event in the progression, invasion and metastasis of malignant head and neck lesions. Imbalances, mutations and polymorphisms of MMPs and their inhibitors are observed in several cancer subtypes. The aim of this study was to evaluate the association of the MMP-7 gene promoter (181 A/G) and MMP-9 (-1562 C/T) polymorphisms in oral tongue squamous cell carcinoma (OTSCC). MMP-7 (rs11568818) and MMP-9 (rs3918242) single-nucleotide polymorphisms (SNPs) were genotyped by polymerase chain reaction-restriction fragment length polymorphism (PCR-RFLP) analysis in 71 cases of OTSCC. Normal tissue specimens were obtained from 60 healthy volunteers to serve as the control. The MMP-7 G allele and MMP-9 T allele were more frequent in the OTSCC group than the control group, but only when these two SNPs were taken together was a significant association found with the nodal metastasis of OTSCC ( $p<0.001)$. Based on our results, SNPs in the promoter region of MMP-7 and MMP-9 appear to be associated with greater risk of developing OTSCC, and with a higher propensity to form metastatic tumors. In this respect, molecular studies investigating polymorphisms may be useful in predicting tumor behavior.
\end{abstract}

Keywords: Metalloproteinases; Mouth Neoplasms.

\section{Introduction}

Oral squamous cell carcinoma (OSCC) is a significant health problem worldwide, representing more than $95 \%$ of primary malignant tumors of the oral cavity. ${ }^{1}$ The latest global estimates indicate that about 300,000 cases were diagnosed and 145,000 deaths occurred in 2012. ${ }^{2}$ The most commonly affected anatomic site is the tongue, and despite advances in treatment, the 5 -year survival rate for this cancer has shown no significant improvement in the last decades, remaining between $50-55 \% .^{3}$ Therefore, efforts are being made to better understand certain differences in the molecular characteristics of neoplastic cells and the tumor microenvironment, aiming at discovering new diagnostic and therapeutic approaches.

The extracellular matrix acts as a structural support network within the tissues, and as a barrier to cell migration. Matrix degradation is mediated by 
the coordinated action of several proteinases, including matrix metalloproteinase (MMPs). MMPs are a family of zinc dependent proteases capable of degrading various components of the extracellular matrix (ECM). Matrix degeneration is a key event in the progression, invasion and metastasis of malignant head and neck lesions. Imbalances in MMPs and their inhibitors are observed in several physiological and pathological conditions, and affect the regulation of several cell behaviors, such as cell proliferation, alteration of cell mobility, angiogenesis and apoptosis. ${ }^{4,5}$

The MMP7 gene (11q21-23) is expressed in a wide variety of normal cells, such as stromal fibroblasts, macrophages, endothelial and epithelial cells, and several malignant cells. ${ }^{5,6}$ Increased expression of MMP-7 has been associated with a poor prognosis in several malignancies, such as OSCC, gastric cancer and renal cancer. ${ }^{7,99}$ The MMP-9 gene (20q11.2-q13.1) codifies an important enzyme for the invasion of adjacent tissues by the tumor through the destruction of ECM components, especially collagen IV ${ }^{10}$ Some studies have investigated the role of MMP-9 in OSCC, and have demonstrated a relationship between the expression of this gelatinase and tumor aggressiveness. ${ }^{11,12}$ Moreover, MMP-9 polymorphisms seem to influence the development of salivary gland neoplasms. ${ }^{13}$

The expression levels of these genes can be influenced by single-nucleotide polymorphisms (SNPs) in their promoter region. $\mathrm{Li}$ et al. ${ }^{14}$ reported that the G allele in the MMP-7 (-181 A/G) gene is associated with greater susceptibility to ovarian cancer, whereas Zhang et al. ${ }^{15}$ associated this allele with a greater risk for the development of esophageal squamous cell carcinoma. The allele of the MMP-9 (-1562 C/T) gene plays a twofold role in MMP-9 genetic transcription. In this respect, the aim of the present study was to investigate the association of MMP-7 (-181 A/G) and $-9(-1562 \mathrm{C} / \mathrm{T})$ gene promoter polymorphisms in metastatic and non-metastatic oral tongue squamous cell carcinoma (OTSCC).

\section{Methodology}

\section{Study subjects}

After approval by the ethics committee (no. 82/2007), 71 patients with OTSCC and 60 healthy controls were evaluated. The healthy controls consisted of individuals with no previous diagnosis of cancer. The data on the OTSCC patients in this study were obtained from medical records. The criteria for inclusion in this study were the presence or absence of cervical metastasis at the time of diagnosis and before the beginning of treatment. Metastasis was confirmed by imaging exams, such as computed tomography or magnetic resonance. Additional inclusion criteria consisted of surgical treatment performed according to standard procedures and comprising resection of the primary tumor, complete clinicopathological data, and availability of paraffin-embedded tumor material. Histopathological grading of the malignancy was performed according to the criteria established by WHO histological grading of malignancy (well-differentiated, moderately differentiated and poorly differentiated). ${ }^{16}$

\section{Isolation of genomic DNA}

Surgical specimens of OTSCC and healthy controls fixed with $10 \%$ formalin and embedded in paraffin were retrieved from the surgical pathology files of the Hospital Dr. Luiz Antônio Oncology Center. DNA from paraffin-embedded tissue was extracted using the QIAamp DNA mini kit (Qiagen, USA), following the protocol of the manufacturer. Concentrations and DNA purity of total DNA were measured by Nanovue GE (GE Healthcare Life Sciences, UK). DNA purity was determined by the A260/A280 curve. Ethidium bromide (EtBr)-stained 1\% agarose gel electrophoresis was used to confirm the presence of genomic DNA in patients and control samples.

\section{Genotyping of the MMP-7 and -9 promoter polymorphisms}

The MMP-7 and -9 genotypes were determined by polymerase chain reaction-restriction length fragment polymorphism (PCR-RFLP) assay. The PCR primers used to amplify the MMP-7 (-181 A/G) (rs11568818) polymorphism were: forward primer (FP) 5'-TGGTACCATAATGTCCTGAATG-3' a $\mathrm{n} d \quad \mathrm{r}$ e ve r s e p ri m e r ( R P ) 5'-TCGTTATTGGCAGGAAGCACACAATGAATT-3'15 Those used for MMP-9 (-1562 C/T) (rs3918242) polymorphism were: forward primer (FP) 
5'- GCCTGGCACATAGTAGGCCC-3' and reverse primer (RP) 5'-CTTCCTAGCCAGCCGGCATC- $3^{\prime} .^{14}$ PCR was performed in a $25 \mu \mathrm{l}$ aliquot containing $100 \mathrm{ng}$ of genomic DNA template, $2.5 \mu \mathrm{l}$ of $10 \times \mathrm{PCR}$ buffer (Invitrogen, Carlsbad, CA, USA), $1.25 \mathrm{mmol}$ of $\mathrm{MgCl} 2$ (Invitrogen, Carlsbad, CA, USA), $1 \mathrm{U}$ of Taq DNA polymerase (Invitrogen, Carlsbad, CA, USA), $1.6 \mathrm{mmol}$ of dNTPs (Invitrogen, Carlsbad, CA, USA), $0.16 \mathrm{nmol}$ of each primer (IDT - Integrated DNA Technologies, Illinois, USA) and Milli-Q water. Distilled water in a PCR reaction mixture was used for the negative control, instead of the DNA sample.

\section{Restriction enzyme digestion of MMP-7 and -9 gene}

A 10- $\mu$ l aliquot of PCR product was digested at $37^{\circ} \mathrm{C}$ overnight in a $15-\mathrm{ml}$ reaction containing $5 \mathrm{U}$ of EcoRI (MMP-7-181 A/G) or SphI (MMP-9 -1562 C/T) and $1 \times$ reaction buffer. After digestion, the products were separated in an $8 \%$ polyacrylamide gel stained with EtBr. As regards MMP-7, after electrophoresis, homozygous AA alleles were represented by a DNA band of $150 \mathrm{bp}$, and homozygous GG alleles were represented by DNA bands with sizes 120 and $30 \mathrm{bp}$, whereas heterozygotes displayed a combination of both alleles (150, 120 and 30 bp); as regards MMP-9, homozygous CC alleles were represented by a DNA band of $435 \mathrm{bp}$, homozygous TT alleles were represented by DNA bands with sizes 247 and 188 bp, whereas heterozygotes displayed a combination of both alleles (435, 247 and $188 \mathrm{bp})$.

\section{Statistical analysis}

Allelic frequencies were determined by direct count of the alleles. Genotypic distributions in the Hardy-Weinberg equilibrium were evaluated by Pearson's chi-square test (two-tailed), according to the classical expression $p^{2}+2 p q+q^{2}=1$. Distribution of the MMP-7 and -9 genotypes in healthy controls and patients did not significantly deviate from that expected for the Hardy-Weinberg equilibrium. Fisher's exact test was used to determine genotype distribution of MMP-7 and -9 between metastatic and non-metastatic OTSCC. Additionally, Pearson's chi-square test was used to compare the distribution of MMP-7 and -9 genotypes between cases and controls. Odds ratio (OR) adjusted for prevalence studies and 95\% confidence intervals were also calculated. A p-value of $<0.05$ was considered statistically significant.

\section{Results}

\section{Clinicopathological features}

The OTSCC was more common in male patients ( $\mathrm{n}=51 / 71.8 \%$ ), with a male to female ratio of 2.5:1. The majority of patients were older than 40 years at diagnosis $(n=62 / 87.3 \%)$. The presence of nodal metastasis was confirmed in 28 patients (39.4\%). The median age of the patients with OTSCC without nodal metastasis was 64.4 years (SD: 13.9; range 70-90), and with nodal metastasis, 56.1 years (SD: 17.7; range 24-96). Forty-one cases of OTSCC (57.7\%) were classified as poorly differentiated, according to WHO histological malignancy grading (Table 1).

\section{Genotype frequencies}

Frequencies of MMP-7 and -9 genotypes are listed in Table 2. Regarding the MMP-7-181G polymorphism, the $G$ allele frequency associated with higher enzyme activity was significantly greater in OTSCC cases (OR 1.4, 95\%CI 1.01-3.98; p < 0.05), compared with the controls. Regarding the MMP-9-1562T polymorphism, the $\mathrm{T}$ allele frequency was significantly greater in OTSCC cases (OR 1.6, 95\%CI 1.05-12.07; p < 0.05), compared with the controls. The heterozygous

Table 1. Demographic and clinical characterization of the cases of oral tongue squamous cell carcinoma studied.

\begin{tabular}{lc}
\hline Variable & OTSCC cases $\mathrm{n}(\%)$ \\
\hline Gender & $51(71.8)$ \\
Male & $20(28.2)$ \\
Female & \\
Age group & $9(12.7)$ \\
$\leq 40$ years & $62(87.3)$ \\
$>41$ & \\
Cervical metastasis & $28(39.4)$ \\
Yes & $43(60.6)$ \\
No & \\
Malignancy grading & $30(42.3)$ \\
Well-differentiated & $41(57.7)$ \\
Poorly differentiated & \\
\hline
\end{tabular}


genotypes of MMP-7 and MMP-9 were associated with OTSCC cases, with a twofold higher risk for the prevalence of these genotypes in individuals with this tumor. Additionally, significant association to OTSCC (OR 2, 95\% CI 1.30-11.40; $\mathrm{p}<0.05$ ) was found when the MMP polymorphic alleles were taken together (MMP-7 A/G or G/G and MMP-9 C/T or T/T).

Our analyses concerning the distribution of SNPs among the clinicopathological features of patients, such as gender, age and malignancy grading, are shown in Table 3. MMP-7 SNP was not associated with age, whereas the heterozygote genotype (OR 1.7, 95\% CI 1.64-11.7; $\mathrm{p}<0.05$ ) and the T allele frequency (OR 1.7, 95\% CI 1.27-19.92; $\mathrm{p}<0.05$ ) of MMP-9 SNP showed an association to patients aged 40 years or older. The same findings were observed in respect to the gender of patients, where the heterozygote genotype (OR 1.7, 95\%CI 1.75-10.9; $\mathrm{p}<0.05$ ) and the $\mathrm{T}$ allele frequency (OR 1.6, 95\%CI 1.0-22.8; $\mathrm{p}<0.05$ ) of MMP-9SNP were strongly linked to male patients, whereas the MMP-7 polymorphism was not. Poorly differentiated OTSCC cases were related to the CT genotype (OR 0.46, 95\%CI 0.11-0.48; $\mathrm{p}<0.05$ ) and the T allele (OR 0.35, 95\%CI 0.06-0.53; $\mathrm{p}<0.05$ ) of MMP-9, whereas the well-differentiated cases showed significant association with the AG genotype (OR 0.63, 95\%CI 0.24-0.77; $\mathrm{p}<0.05$ ) and G allele (OR 0.61, 95\%CI 0.20-0.82; $\mathrm{p}<0.05$ ) of MMP-7.

The relationship between genotypes and nodal metastasis was evaluated by Fisher's exact test (Table 4).

Table 2. Distribution of MMP-7 and -9 genotypes in OTSCC and controls.

\begin{tabular}{|c|c|c|c|c|c|}
\hline MMP & Genotype & OTSCC & Control & Odds Ratio (95\%Cl) & $p$-value* \\
\hline \multirow{4}{*}{ MMP-7 } & $\mathrm{A} / \mathrm{A}$ & $33(46 \%)$ & $44(73 \%)$ & $0.32(0.17-0.57)$ & $<0.001$ \\
\hline & $A / G$ & $36(51 \%)$ & $12(20 \%)$ & $2.00(2.22-7.87)$ & $<0.001$ \\
\hline & $G / G$ & 2 (3\%) & $4(7 \%)$ & $0.41(0.07-1.87)$ & 0.331 \\
\hline & Allele G & $28 \%$ & $16 \%$ & $1.40(1.01-3.98)$ & 0.044 \\
\hline \multirow{4}{*}{ MMP-9 } & $\mathrm{C} / \mathrm{C}$ & $56(79 \%)$ & $55(92 \%)$ & $0.33(0.13-0.77)$ & 0.009 \\
\hline & $\mathrm{C} / \mathrm{T}$ & $14(20 \%)$ & $5(8 \%)$ & $1.54(1.21-7.23)$ & 0.014 \\
\hline & $\mathrm{T} / \mathrm{T}$ & 1 (1\%) & $0(0)$ & - & - \\
\hline & Allele T & $12 \%$ & $4 \%$ & $1.60(1.05-12.07)$ & 0.06 \\
\hline MMP-7 + MMP-9 & $\mathrm{A} / \mathrm{G}, \mathrm{G} / \mathrm{G}+\mathrm{C} / \mathrm{T}, \mathrm{T} / \mathrm{T}$ & $11(15 \%)$ & $3(5 \%)$ & $2.00(1.30-11.40)$ & 0.011 \\
\hline
\end{tabular}

*Pearson's chi-square test.

Table 3. Age group, gender, malignancy grading and genotypic distribution of MMP-7 and MMP-9 SNPs in the cases of OTSCC studied.

\begin{tabular}{|c|c|c|c|c|c|c|c|c|c|}
\hline \multirow{4}{*}{ Variable } & \multirow{4}{*}{$\begin{array}{c}\text { OTSCC } \\
\text { n (\%) }\end{array}$} & \multicolumn{8}{|c|}{ Genotypic distribution } \\
\hline & & \multicolumn{4}{|c|}{ MMP-7 - 181A/G } & \multicolumn{4}{|c|}{ MMP-9 - 1562C/T } \\
\hline & & AA & $A G$ & GG & Allele G & CC & CT & $\mathrm{TT}$ & Allele T \\
\hline & & $\mathrm{n}(\%)$ & $\mathrm{n}(\%)$ & n (\%) & $(\%)$ & $\mathrm{n}(\%)$ & n (\%) & $n(\%)$ & $(\%)$ \\
\hline \multicolumn{10}{|l|}{ Age group } \\
\hline$<40$ years & $9(12.7)$ & $2(22)$ & $5(56)$ & $2(22)$ & 50 & $8(89)$ & $1(11)$ & - & 6 \\
\hline$\geq 40$ & 62 (87.3) & $31(50)$ & $31(50)$ & - & 25 & $48(77)$ & $13(21)^{a}$ & $1(2)$ & $12^{b}$ \\
\hline \multicolumn{10}{|l|}{ Gender } \\
\hline Male & 51 (71.8) & 25 (49) & 25 (49) & $1(2)$ & 26 & $39(76)$ & $12(24)^{c}$ & - & $14^{\mathrm{d}}$ \\
\hline Female & $20(28.2)$ & $8(40)$ & $11(55)$ & $1(5)$ & 32 & $17(85)$ & $2(10)$ & $1(5)$ & 10 \\
\hline \multicolumn{10}{|l|}{ Malignancy grading } \\
\hline Well differentiated & $30(42.3)$ & $16(53)$ & $13(43)^{\mathrm{e}}$ & $1(4)^{f}$ & 46 & $26(86)$ & $4(14)$ & - & 14 \\
\hline Poorly differentiated & $41(57.7)$ & $17(41)$ & $23(56)$ & $1(3)$ & 58 & $30(73)$ & $10(24)^{\mathrm{g}}$ & $1(3)$ & $27^{\mathrm{h}}$ \\
\hline
\end{tabular}


Frequency of the MMP-7-181G allele (27\%) was more prevalent than the MMP-9-1562 T allele (5\%) in metastatic cases. However, there was a significant association between these polymorphisms and nodal metastasis only when the SNPs were taken together in the analyses (MMP-7 A/G or G/G and MMP-9 C/T or T/T) (OR 2, 95\% CI 2.18-13.31; P<0.05). Individually, heterozygote genotype and T allele frequency of MMP-9SNP showed a significant relation to non-metastatic OTSCC cases.

\section{Discussion}

Polymorphisms in the extracellular matrix metalloproteinases (MMP) promoter regions, resulting from nucleotide insertions or substitutions, or from microsatellite instability, change the relationship between transcription factors and cis elements in the promoter. ${ }^{15,16,17}$. Zhang et al. ${ }^{15}$ demonstrated that the substitution of a cytosine for a thymine $(\mathrm{C} \rightarrow \mathrm{T})$ in the -1562 position of the MMP-9 promoter generates a high affinity site for a yet unidentified nuclear protein, leading to an expressive increase in the promoter activity of the MMP gene. On the other hand, the single nucleotide polymorphism (SNP) at position -181 of the MMP-7 promoter also exerts a significant effect on the expression of this metalloenzyme, because it substitutes an adenine with a guanine $(A \rightarrow G)$, thus generating a binding site for a heat shock transcription factor (HSTF). ${ }^{17}$

In this respect, although several studies have detected high levels of MMP-7 and MMP-9 protein expression in OSCC, particularly in the tongue, $7,12,18$ few studies have evaluated the possible relationship between the presence of functional SNPs in these metalloproteinases, and the clinical development or aggressiveness of this type of neoplasia.

Individually, the MMP-7 -181 G and MMP-9-1562 T polymorphic allele frequencies were higher in OTSCC patients compared with the control group. These results corroborate those reported by Blons et al. ${ }^{19}$ and Vairaktaris et al. ${ }^{20}$, who also observed that the MMP-7 G allele was more prevalent in 148 cases of squamous cell carcinoma of the head and neck, and in 159 cases of OSCC, compared with the controls. Additionally, some authors detected a more frequent association of the MMP-9 T allele in OSCC cases. ${ }^{20,21}$

Significantly, the heterozygous genotypes of MMP-7 and MMP-9 have been strongly associated with OTSCC cases, with a twofold higher risk of prevalence of these genotypes in individuals affected by this neoplasm. Indeed, all genotypes of MMP-7 and MMP-9 presenting polymorphic alleles (A/G and G/G for MMP-7; C/T and C/C for MMP-9) showed significant association in OTSCC patients, with a prevalence risk higher than that of the control individuals. This reinforces the probable role of these SNPs in the development of oral cancer.

The relationship between MMP-7 -181 A/G and MMP-9 -1562 C/T SNPs, with the risk of developing other diseases, seems to be in line with our results. Li et al. ${ }^{14}$, in a case-control study of 138 ovarian cancer cases, detected a possible association between the MMP-7 A/G polymorphism and the risk of developing ovarian cancer, but did not associate the

Table 4. Distribution of MMP-7 and -9 genotypes in OTSCC and control according to nodal metastasis.

\begin{tabular}{|c|c|c|c|c|c|}
\hline \multirow{2}{*}{ MMP } & \multirow{2}{*}{ Genotype } & \multicolumn{2}{|c|}{ Metastasis } & \multirow{2}{*}{ Odds Ratio (95\%Cl) } & \multirow{2}{*}{$\mathrm{p}$-value* } \\
\hline & & Absent & Present & & \\
\hline \multirow{4}{*}{ MMP-7 } & $\mathrm{A} / \mathrm{A}$ & 19 (45\%) & $14(50 \%)$ & $1.10(0.70-2.14)$ & 0.479 \\
\hline & $A / G$ & $23(53 \%)$ & $13(46 \%)$ & $0.76(0.43-1.32)$ & 0.322 \\
\hline & $G / G$ & $1(2 \%)$ & $1(4 \%)$ & $1.34(0.28-22.98)$ & 0.683 \\
\hline & Allele G & $30 \%$ & $27 \%$ & $1.00(0.46-1.60)$ & 0.638 \\
\hline \multirow{4}{*}{ MMP-9 } & $\mathrm{C} / \mathrm{C}$ & $31(72 \%)$ & $25(89 \%)$ & $2.00(1.48-6.96)$ & 0.202 \\
\hline & $\mathrm{C} / \mathrm{T}$ & $11(26 \%)$ & $3(11 \%)$ & $0.53(0.16-0.76)$ & 0.006 \\
\hline & $\mathrm{T} / \mathrm{T}$ & $1(2 \%)$ & $0(0)$ & - & - \\
\hline & Allele $\mathrm{T}$ & $15 \%$ & $5 \%$ & $0.48(0.09-0.48)$ & 0.018 \\
\hline MMP-7 + MMP-9 & $\mathrm{A} / \mathrm{G}, \mathrm{G} / \mathrm{G}+\mathrm{C} / \mathrm{T}, \mathrm{T} / \mathrm{T}$ & $3(7 \%)$ & $8(28 \%)$ & $2.00(2.18-13.31)$ & $<0.001$ \\
\hline
\end{tabular}

*Fisher's exact test. 
MMP-9-1562 C/T SNP with this same risk. A similar result was reported by Horvat et al., ${ }^{22}$ who observed a greater risk for colorectal cancer in patients with MMP7 SNP. Moreover, Banday et al. ${ }^{23}$ also observed an association between MMP-2, -7 and -9SNPs, and the risk of developing the same type of cancer.

In relation to the distribution of SNPs among the clinical features of patients and controls, MMP-7 SNP was not associated with age or gender, whereas the heterozygote genotype and the T allele of MMP-9SNP showed an association with male patients aged 40 years and older, and with poorly differentiated tumors.

The formation of metastatic tumors is strongly related to high recurrence and low survival rates, and to low OTSCC disease free time. In the analysis of the individual distribution of the MMP-7 -181 A/G and MMP-9-1562 C/T polymorphisms among OTSCC cases with or without nodal metastasis, no statistically significant association between the frequency of these SNPs and metastatic cases was detected. On the other hand, when present in the same patient, both SNPs exhibited a strong association, as well as a twofold higher risk of their prevalence in metastatic OTSCC cases. Consequently, considering previous observations for the combined frequency of the SNPs evaluated, people carrying two genotypes containing the MMP-7 and MMP-9 polymorphisms appear to present a higher risk of developing OTSCC, with a higher propensity to form metastatic tumors.

Ghilardi et al..$^{24}$ conducted a retrospective case-control study of the frequency of the $181 \mathrm{~A} / \mathrm{GSNP}$ in the promoter sequence of the MMP-7 gene in cases of colorectal carcinoma, and inferred that this polymorphism not only played a role in neoplastic development, but also had a relation to the lymph node metastasis of this type of cancer. Matsumara et al. ${ }^{25}$ also reported that the polymorphic $-1562 \mathrm{~T}$ allele of MMP-9 was related to the invasive phenotype of malignant cells from gastric cancer. These findings were also observed by other authors in patients with colorectal cancer. ${ }^{22,23}$

Unlike the polymorphic $\mathrm{T}$ allele, the wild-type MMP-9 C allele exhibited a significant association with metastatic OTSCC cases, with a twofold higher risk of prevalence. However, this samewild-typeallele displayed no association with OTSCC development. Thus, this finding suggests that individuals with OTSCC and carriers of the wild-type C allele located in the MMP-9 (-1562) promoter are more likely to develop metastases than those carrying the functional polymorphic variant $\mathrm{T}$. Corroborating this last result, Grieu et al. ${ }^{26}$ conducted a study with 251 patients with breast cancer, and found that the distribution of the wild-type MMP-9 -1562 C allele was associated with well-established poor prognosis characteristics for this type of cancer.

\section{Conclusions}

In summary, these significant findings indicate that the interindividual genetic variability that increases the susceptibility or prevention of a given disease are largely complex. The results of this study show that the frequency of SNPs located in the sequence of the MMP-7 (-181) and MMP-9 (-1562) promoter genes presented a significant association with the OTSCC cases evaluated, both separately and in combination in the same patient. However, these polymorphic variants were associated with metastasis only when their frequencies were observed in combination.

\section{References}

1. Marocchio LS, Lima J, Sperandio FF, Corrêa L, de Sousa SO. Oral squamous cell carcinoma: an analysis of 1,564 cases showing advances in early detection. J Oral Sci. 2010 Jun;52(2):267-73. https://doi.org/10.2334/josnusd.52.267

2. Ferlay J, Steliarova-Foucher E, Lortet-Tieulent J, Rosso S, Coebergh JW, Comber H, et al. Cancer incidence and mortality patterns in Europe: estimates for 40 countries in 2012. Eur J Cancer. 2013 Apr;49(6):1374-403. https://doi.org/10.1016/i.ejca.2012.12.027

3. Thiagarajan S, Nair S, Nair D, Chaturvedi P, Kane SV, Agarwal JP, et al. Predictors of prognosis for squamous cell carcinoma of oral tongue. J Surg Oncol. 2014 Jun;109(7):639-44. https://doi.org/10.1002/iso.23583

4. Lambert E, Dassé E, Haye B, Petitfrère E. TIMPs as multifacial proteins. Crit Rev Oncol Hematol. 2004 Mar;49(3):187-98. https://doi.org/10.1016/i.critrevonc.2003.09.008 
5. Egeblad M, Werb Z. New functions for the matrix metalloproteinases in cancer progression. Nat Rev Cancer. 2002 Mar;2(3):161-74. https://doi.org/10.1038/nrc745 PMID:11990853

6. Sternlicht MD, Werb Z. How matrix metalloproteinases regulate cell behavior. Annu Rev Cell Dev Biol. 2001;17(1):463-516. https://doi.org/10.1146/annurev.cellbio.17.1.463

7. Amorim RF, Silveira EJ, Queiroz LM, Galvão HC, Souza LB, Freitas RA. Matrilysins may not predict the metastatic potential in squamous cell carcinoma of the tongue. Acta Odontol Scand. 2010 Jul;68(4):228-31. https://doi.org/10.3109/00016357.2010.490955

8. Yeh YC, Sheu BS, Cheng HC, Wang YL, Yang HB, Wu JJ. Elevated serum matrix metalloproteinase-3 and -7 in H. pylori-related gastric cancer can be biomarkers correlating with a poor survival. Dig Dis Sci. 2010 Jun;55(6):1649-57. https://doi.org/10.1007/s10620-009-0926-x

9. Ramankulov A, Lein M, Johannsen M, Schrader M, Miller K, Jung K. Plasma matrix metalloproteinase-7 as a metastatic marker and survival predictor in patients with renal cell carcinomas. Cancer Sci. 2008 Jun;99(6):1188-94. https://doi.org/10.1111/j.1349-7006.2008.00802.x

10. Engsig MT, Chen QJ, Vu TH, Pedersen AC, Therkidsen B, Lund LR, et al. Matrix metalloproteinase 9 and vascular endothelial growth factor are essential for osteoclast recruitment into developing long bones. J Cell Biol. 2000 Nov; 151(4):879-89. https://doi.org/10.1083/jcb.151.4.879

11. Katayama A, Bandoh N, Kishibe K, Takahara M, Ogino T, Nonaka S, et al. Expressions of matrix metalloproteinases in early-stage oral squamous cell carcinoma as predictive indicators for tumor metastases and prognosis. Clin Cancer Res. 2004 Jan;10(2):634-40. https://doi.org/10.1158/1078-0432.CCR-0864-02

12. Tanaka T, Imamura T, Yoneda M, Irie A, Ogi H, Nagata M, et al. Enhancement of active MMP release and invasive activity of lymph node metastatic tongue cancer cells by elevated signaling via the TNF- $\alpha$-TNFR1-NF- $\kappa B$ pathway and a possible involvement of angiopoietin-like 4 in lung metastasis. Int J Oncol. 2016 Oct;49(4):1377-84. https://doi.org/10.3892/ijo.2016.3653

13. Radunovic M, Nikolic N, Milenkovic S, Tomanovic N, Boricic I, Dimitrijevic M, et al. The MMP-2 and MMP-9 promoter polymorphisms and susceptibility to salivary gland cancer. J BUON. 2016 May-Jun;21(3):597-602.

14. Li Y, Jin X, Kang S, Wang Y, Du H, Zhang J, et al. Polymorphisms in the promoter regions of the matrix metalloproteinases-1, $-3,-7$, and -9 and the risk of epithelial ovarian cancer in China. Gynecol Oncol. 2006 Apr;101(1):92-6. https://doi.org/10.1016/i.ygyno.2005.09.058

15. Zhang J, Jin X, Fang S, Wang R, Li Y, Wang N, et al. The functional polymorphism in the matrix metalloproteinase-7 promoter increases susceptibility to esophageal squamous cell carcinoma, gastric cardiac adenocarcinoma and non-small cell lung carcinoma. Carcinogenesis. 2005 Oct;26(10):1748-53. https://doi.org/10.1093/carcin/bgi144

16. Müller S. Update from the 4th edition of the World Health Organization of Head and Neck Tumours: tumours of the oral cavity and mobile tongue. Head Neck Pathol. 2017 Mar;11(1):33-40. https://doi.org/10.1007/s12105-017-0792-3

17. Jormsjö S, Whatling C, Walter DH, Zeiher AM, Hamsten A, Eriksson P. Allele-specific regulation of matrix metalloproteinase-7 promoter activity is associated with coronary artery luminal dimensions among hypercholesterolemic patients. Arterioscler Thromb Vasc Biol. 2001 Nov;21(11):1834-9. https://doi.org/10.1161/hq1101.098229

18. Barros SS, Henriques ÁC, Pereira KM, Medeiros AM, Galvão HC, Freitas RA. Immunohistochemical expression of matrix metalloproteinases in squamous cell carcinoma of the tongue and lower lip. Arch Oral Biol. 2011 Aug;56(8):752-60. https://doi.org/10.1016/i.archoralbio.2010.11.022

19. Blons H, Gad S, Zinzindohové F, Manière I, Beauregard J, Tregouet D, et al. Matrix metalloproteinase 3 polymorphism: a predictive factor of response to neoadjuvant chemotherapy in head and neck squamous cell carcinoma. Clin Cancer Res. 2004 Apr;10(8):2594-9. https://doi.org/10.1158/1078-0432.CCR-1116-03

20. Vairaktaris E, Serefoglou Z, Yapijakis C, Vylliotis A, Nkenke E, Derka S, et al. High gene expression of matrix metalloproteinase-7 is associated with early stages of oral cancer. Anticancer Res. 2007 Jul-Aug;27 4B:2493-8.

21. Vairaktaris E, Serefoglou Z, Avgoustidis D, Yapijakis C, Critselis E, Vylliotis A, et al. Gene polymorphisms related to angiogenesis, inflammation and thrombosis that influence risk for oral cancer. Oral Oncol. 2009 Mar;45(3):247-53. https://doi.org/10.1016/i.oraloncology.2008.05.003

22. Horvat M, Potocnik U, Repnik K, Kavalar R, Zadnik V, Potrc S, et al. Single Nucleotide Polymorphisms in Genes MACC1, RAD18, MMP7 and SDF-la As Prognostic Factors in Resectable Colorectal Cancer. Radiol Oncol. 2016 Sep;51(2):151-9. https://doi.org/10.1515/raon-2016-0043

23. Banday MZ, Sameer AS, Mir AH, Mokhdomi TA, Chowdri NA, Haq E. Matrix metalloproteinase (MMP) -2, -7 and -9 promoter polymorphisms in colorectal cancer in ethnic Kashmiri population - A case-control study and a mini review. Gene. 2016 Sep;589(1):81-9. https://doi.org/10.1016/i.gene.2016.05.028

24. Ghilardi G, Biondi ML, Erario M, Guagnellini E, Scorza R. Colorectal carcinoma susceptibility and metastases are associated with matrix metalloproteinase-7 promoter polymorphisms. Clin Chem. 2003 Nov;49(11):1940-2. https://doi.org/10.1373/clinchem.2003.018911

25. Matsumura S, Oue N, Nakayama H, Kitadai Y, Yoshida K, Yamaguchi Y, et al. A single nucleotide polymorphism in the MMP-9 promoter affects tumor progression and invasive phenotype of gastric cancer. J Cancer Res Clin Oncol. 2005 Jan;131(1):19-25. https://doi.org/10.1007/s00432-004-0621-4

26. Grieu F, Li WQ, lacopetta B. Genetic polymorphisms in the MMP-2 and MMP-9 genes and breast cancer phenotype. Breast Cancer Res Treat. 2004 Dec;88(3):197-204. https://doi.org/10.1007/s10549-004-0595-6 